We did not attempt to retrieve the device percutaneously because of the fear of more distal embolization. The patient was taken to the operating room soon after the diagnosis was made. An interesting situation arose when the device could not be found in the ascending aorta, where it was initially reported to be present. We think that initiation of femoral bypass resulted in the device being pushed back into the proximal aorta. With subsequent aortic crossclamping and antegrade cold blood cardioplegia, it slipped through the aortic valve into the left ventricle and got entangled in the submitral apparatus.

The decision to start the patient on deep hypothermia with plans of circulatory arrest was made for fear of distal embolization during aortic manipulation. It seems that the femoral artery bypass pressure helped by pushing the device back near the aortic valve and, with subsequent antegrade cardioplegia, pushed the device through the aortic valve into the left ventricle and then toward the left atrium, and this saved the patient from an aortic intervention. This phenomenon has not been described in the literature to the best of our knowledge.
We propose that when an ASO has embolized to the aorta, femoral cannulation and cardiopulmonary bypass, along with transesophageal echocardiography and fluoroscopy to localize the device accurately, should be used.

\section{References}

1. Spies C, Timmermanns I, Schrader R. Transcatheter closure of secundum atrial septal defects in adults with the Amplatzer septal occluder: intermediate and long-term results. Clin Res Cardiol. 2007;96:340-6.

2. Chessa M, Carminati M, Butera G, Bini RM, Drago M, Rosti L, et al. Early and late complications associated with transcatheter occlusion of secundum atrial septal defect. J Am Coll Cardiol. 2002;39:1061-5.

3. Fischer G, Stieh J, Uebing A, Hoffmann U, Morf G, Kramer HH. Experience with transcatheter closure of secundum atrial septal defects using the Amplatzer septal occluder: a single centre study in 236 consecutive patients. Heart. 2003;89:199-204.

4. Du ZD, Hijazi ZM, Kleinman CS, Silverman NH, Larntz K. Amplatzer Investigators. Comparison between transcatheter and surgical closure of secundum atrial septal defect in children and adults: results of a multicenter nonrandomized trial. J Am Coll Cardiol. 2002;39:1836-44.

\title{
Thoracic endovascular aortic repair of adult patent ductus arteriosus with pulmonary hypertension
}

\author{
Yong-Qiang Lai, MD, ${ }^{a}$ Shang-Dong Xu, MD, ${ }^{a}$ Zhi-Zhong Li, MD, ${ }^{\mathrm{b}}$ Bao-Zhong Yang, MD, ${ }^{\mathrm{c}}$ Su Wang, MD, ${ }^{\mathrm{b}}$ Jin-Hua Li, MD, \\ Jing-Wei Li, MD, ${ }^{a}$ Yi Luo, MD, ${ }^{a}$ and Zhao-Guang Zhang, MD, ${ }^{a}$ Beijing, China
}

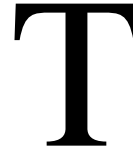

horacic endovascular aortic repair (TEVAR) has emerged as an alternative treatment for adult patent ductus arteriosus (PDA) in recent years. ${ }^{1}$ We report here our preliminary experience in treating adult PDA with stent-grafts.

\section{Clinical Summary}

From September 2005 to March 2007, a total of 4 patients with a large PDA and pulmonary hypertension underwent TEVAR. All patients had exertional dyspnea. Transthoracic echocardiography, computed tomographic angiography, and right heart catheterization were conducted before the operation. All patients had severe pulmonary hypertension. Indications for stent-graft implantation were as follows: (1) adult patient with large PDA, (2) no other congenital

From the Divisions of Cardiac Surgery, ${ }^{\mathrm{a}}$ Cardiology, ${ }^{\mathrm{b}}$ and Vascular Surgery, ${ }^{\mathrm{C}}$ Beijing Anzhen Hospital, Beijing Institute of Heart, Lung, \& Vascular Diseases, Capital Medical University, Beijing, China.

Received for publication Sept 3, 2007; accepted for publication Nov 26, 2007.

Address for reprints: Yong-Qiang Lai, MD, Division of Cardiac Surgery, Beijing Anzhen Hospital, 36 Wuluju Chaoyang District, Beijing, China, 100029 (E-mail: yongqianglai@yahoo.com).

J Thorac Cardiovasc Surg 2008;135:699-701

0022-5223/ $\$ 34.00$

Copyright $@ 2008$ by The American Association for Thoracic Surgery doi:10.1016/j.jtcvs.2007.11.028

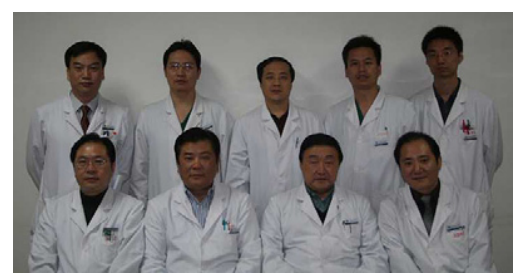

Drs $\mathrm{Xu}, \mathrm{J}-\mathrm{W} \mathrm{Li}, \mathrm{Z}-\mathrm{Z} \mathrm{Li}, \mathrm{J}-\mathrm{H} \mathrm{Li}$, and Wang (top row, left to right); Drs Yang, Luo, Zhang, and Lai (bottom row, left to right).

cardiac defects, (3) no right-to-left shunt, (4) adequate landing zone (arch diameter $<35 \mathrm{~mm}$ ), and (5) adequate access route. The study was approved by the institutional review board, and informed consent was obtained. Clinical data are summarized in Table 1.

TEVAR was performed in a catheter laboratory with general anesthesia. The TEVAR procedure is described in detail in our previous article. ${ }^{4}$ Brachial and pulmonary arterial pressures were monitored. Different arteries were used as access routes. The right common femoral artery was used in 2 patients. Transperitoneal exposure of the abdominal aorta was performed in 1 patient. The common iliac artery was mobilized through the postperitoneal approach by a left oblique hypogastric incision in 1 patient. Tapered stentgrafts (Grikin Advanced Materials Co, Ltd, Beijing, China) were used. The left subclavian artery (LSCA) was covered simultaneously in all patients.

Stent-grafts were successfully implanted in all patients. Mean pulmonary arterial pressure decreased from $65.8 \pm 8.4 \mathrm{~mm} \mathrm{Hg}$ 
TABLE 1. Patient data

\begin{tabular}{|c|c|c|c|c|c|}
\hline & Case 1 & Case 2 & Case 3 & Case $4^{*}$ & Mean \pm SD \\
\hline Sex & Female & Female & Female & Female & \\
\hline Age (y) & 17 & 37 & 30 & 42 & $31.5 \pm 5.4$ \\
\hline $\begin{array}{l}\text { Pulmonary opening } \\
\text { diameter of PDA } \\
(\mathrm{mm})\end{array}$ & 16 & 12 & 22 & 14 & $16.0 \pm 2.1$ \\
\hline $\begin{array}{l}\text { Aortic opening } \\
\text { diameter of PDA } \\
(\mathrm{mm})\end{array}$ & 30 & 28 & 26 & 29 & $28.3 \pm 0.8$ \\
\hline \multicolumn{6}{|c|}{ Stent-graft dimensions (mm) } \\
\hline Proximal diameter & 30 & 36 & 34 & 34,32 & \\
\hline Length & 100 & 120 & 120 & 85,100 & \\
\hline Distal diameter & 26 & 30 & 28 & 30,28 & \\
\hline $\begin{array}{l}\text { Preoperative MPAP } \\
\qquad(\mathrm{mm} \mathrm{Hg})\end{array}$ & 75 & 45 & 60 & 83 & $65.8 \pm 8.4$ \\
\hline $\begin{array}{l}\text { Postoperative MPAP } \\
\text { (mm Hg) }\end{array}$ & 50 & 20 & 38 & 54 & $40.5 \pm 7.6$ \\
\hline Follow-up (mo) & 18 & 15 & 6 & 3 & $10.5 \pm 3.6$ \\
\hline
\end{tabular}

PDA, Patent ductus arteriosus; MPAP, Mean pulmonary arterial pressure. *Patient had two grafts placed.

to $40.5 \pm 7.6 \mathrm{~mm} \mathrm{Hg}(P<.05)$. Postoperative course was uneventful. Complete occlusion of the PDA was achieved immediately after stent-graft implantation in 3 patients (Figure 1). A cuff was added in 1 patient during the procedure, but there was still trivial left-to-right shunt. Before discharge, however, the shunt could no longer be seen with transthoracic echocardiography and computed tomographic angiography. There were no complications (eg, left arm claudication or vertebrobasilar insufficiency) either after the operation or during follow-up.

All patients were followed up for 3 to 18 months (average 10.5 months). Transthoracic echocardiographic examinations were performed at discharge, at 1 postoperative month, and once a year after the procedure. Computed tomographic angiography was conducted at discharge and once a year after the procedure. Transthoracic echocardiography 1 month after the procedure showed that the left ventricle end-diastolic diameter had diminished from a preoperative value of $64.3 \pm 6.9 \mathrm{~mm}$ to a postoperative value of $56.5 \pm 6.1 \mathrm{~mm}(P<.05)$.

\section{Discussion}

Because of the fragility of the aorta and aneurysmal change of the ductus, the surgical closure (whether through a left thoracotomy or sternotomy) of PDA in adult patients carries a high risk. When severe pulmonary hypertension is present, the risk of surgical repair of PDA increases dramatically, especially when the transpulmonary closure technique is used with hypothermic circulatory arrest. ${ }^{2}$ Transcatheter closure with umbrella or spring coil has proved to be an effective and safe treatment. When a large PDA and severe pulmonary hypertension are present, however, transcatheter closure can be problematic. The most serious complication is the dislodgment of the umbrella. ${ }^{3}$

Use of TEVAR to occlude the aortic opening of a PDA is a reasonable alternative for the correction of this anomaly. The procedure is less invasive than is open-chest surgery. Moreover, it is more secure than an umbrella. Our early results are encouraging.

Because of the large left-to-right shunt at the level of descending aorta and less blood going to the lower body, the diameter of the common femoral artery was small in our patients. Preoperative evaluation of femoral and iliac arteries with ultrasonography is important. If the common femoral artery is small (diameter $<7 \mathrm{~mm}$ ), then the common iliac artery or even abdominal aorta should be considered. The common iliac artery can be exposed through a postperitoneal approach with a left oblique hypogastric incision.

A sufficient proximal landing zone is essential for stent-graft landing and PDA sealing. The LSCA was sacrificed in all of our patients because of its proximity to the PDA. Because we considered this procedure relatively safe in light of our previous experience, ${ }^{4}$ no preoperative tests were performed to demonstrate its safety. There were no complications related to the occlusion of the LSCA, either after the operation or during follow-up. A stent-graft with fenestration or a side arm might preserve the blood flow to the LSCA5; however, such stent-grafts are not yet available for purchase.

Early results of TEVAR of PDA are encouraging. As such, TEVAR may be a therapeutic alternative for adult patients with large PDA and pulmonary hypertension. Long-term follow-ups are needed.

\section{References}

1. Roques F, Hennequin JL, Sanchez B, Ridarch A, Rousseau H. Aortic stent-graft for patent ductus arteriosus in adults: the aortic exclusion technique. Ann Thorac Surg. 2001;71:1708-9.

2. Toda R, Moriyama $Y$, Yamashita M, Iguro $Y$, Matsumoto $H$, Yotsumoto G. Operation for adult patent ductus arteriosus using cardiopulmonary bypass. Ann Thorac Surg. 2000;70:1935-7.

3. Yan C, Zhao S, Jiang S, Xu Z, Huang L, Zheng H, et al. Transcatheter closure of patent ductus arteriosus with severe pulmonary arterial hypertension in adults. Heart. 2007;93:514-8.

4. Xu SD, Huang FJ, Yang JF, Li ZZ, Wang XY, Zhang ZG, et al. Endovascular repair of acute type B aortic dissection: early and mid-term results. J Vasc Surg. 2006;43:1090-5.

5. Saito N, Kimura T, Toma M, Sasaki K, Kita T, Imura M, et al. Transcatheter closure of patent ductus arteriosus with the Inoue single-branched stent graft. J Thorac Cardiovasc Surg. 2005;130:1203-4. 

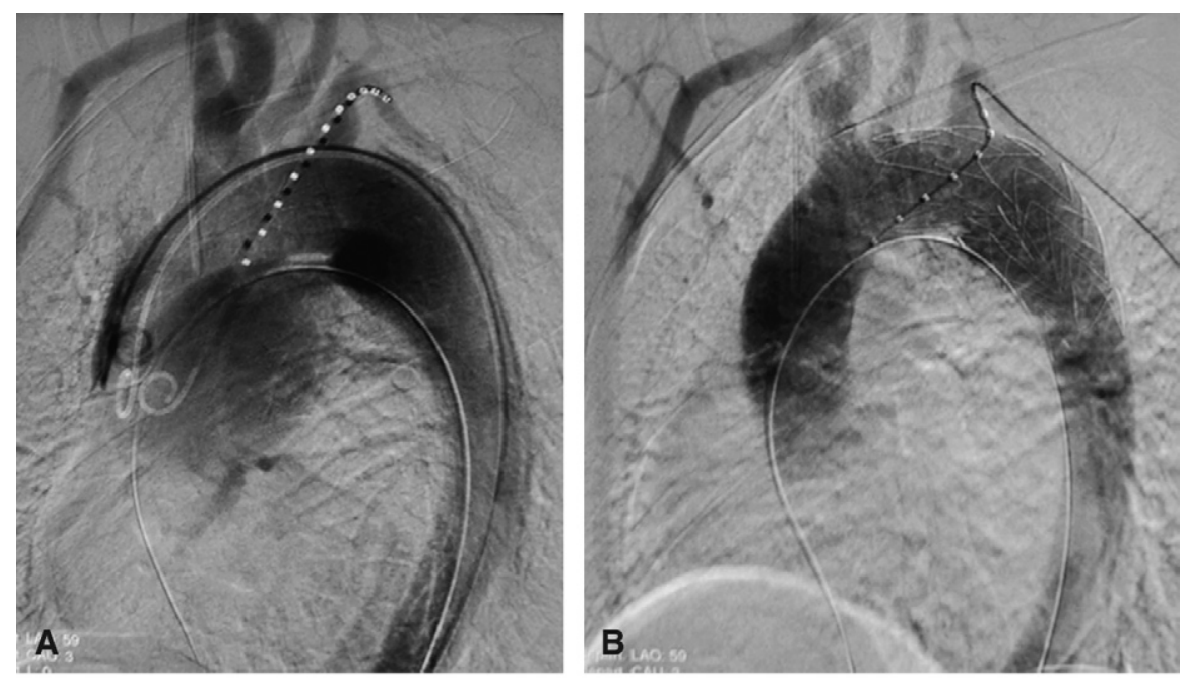

Figure 1. A, Digital subtraction angiography before stent-graft implantation. $B$, Digital subtraction angiography after stent-graft implantation. C, Computed tomographic angiography before procedure. D, Computer tomographic angiography after procedure.
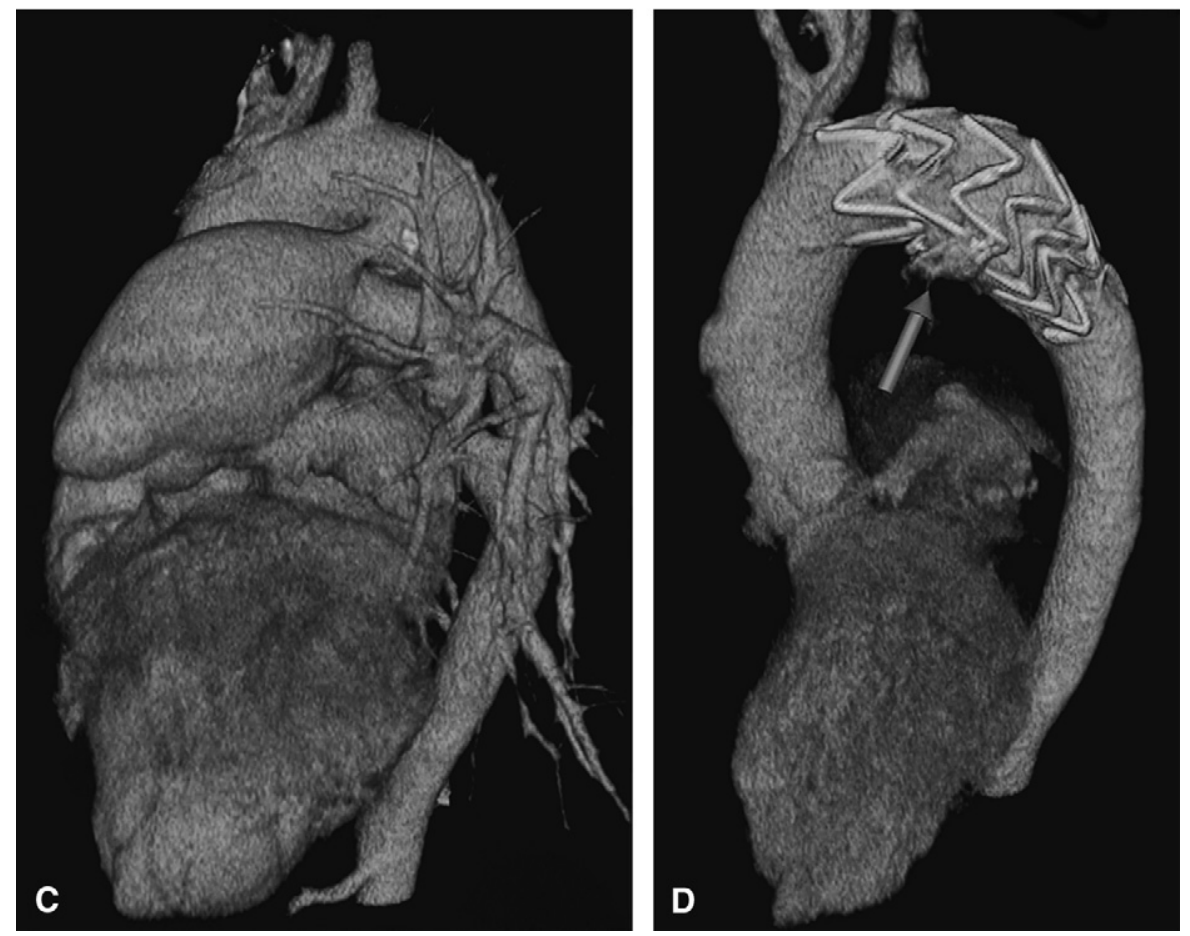